\title{
KEJADIAN LUAR BIASA KERACUNAN "CUMI-CUMIAN" DI SEKOLAH DASAR NEGERI 1 TRASAN BANDONGAN KABUPATEN MAGELANG
}

\section{OUTBREAK BY "CALAMARI LIKE" POISONING AT ELEMENTARY SCHOOL 1 TRASAN BANDONGAN MAGELANG DISTRICT}

\author{
Nasir Ahmad ${ }^{1 *}$, Adi Isworo ${ }^{2}$, Citra Indriani ${ }^{3}$ \\ ${ }^{* 1}$ Program Studi Kesehatan Masyarakat, Sekolah Tinggi Ilmu Kesehatan Jenderal Achmad Yani Cimahi, \\ Jalan Terusan Jenderal Sudirman Cimahi 40533, Email: nasirahmad3443@gmail.com, Indonesia \\ ${ }^{2}$ Politeknik Kesehatan, Kementrian Kesehatan Republik Indonesia, JI. Perintis Kemerdekaan, Kramat Utara, \\ Magelang Utara, Kota Magelang, Jawa Tengah 56115, Indonesia \\ ${ }^{3}$ Field Epidemiology Training Programs (FETP), Universitas Gadjah Mada, Jl. Farmako, Sekip Utara, 55281, \\ Sinduadi, Mlati, Kabupaten Sleman, Daerah Istimewa Yogyakarta, Indonesia
}

\begin{abstract}
Background: On May $4^{\text {th }}, 2016$, at 12:30 district surveillance officer of Magelang Health Department received reports from Public Health Center of Bandongan about 21 students of SDN 1 Trasan who suffered from the same food-poisoning symptoms.

Objective: Investigation was carried out to identify the source, how it spread and how to control it.

Methods: This study used descriptive analytic and mapping the cases distribution location. The case was people experiencing symptoms of dizziness or abdominal pain or nausea or vomiting. Data analysis was done by using bivariate analysis. Data collection were done through interviews, observations and laboratory tests on the food samples.

Results: The case was 50 students (from 1-6 grade students). The perceived symptoms were dizziness $(77 \%)$, nausea $(42 \%)$, abdominal pain $(40 \%)$ and vomiting (8\%). Attack rate found ranged from $14.3 \%$ to $60 \%$ with the highest Attack rate found on class three (60\%). The incubation period of 15-240 minutes (mean 72.3 minutes). Calamari like positive Bacillus cereus and Rhodamine-B $10 \mathrm{mg} / \mathrm{kg}$.

Conclusion: The outbreak of food poisoning because calamari like contaminated Bacillus cereus. We suggested the school committee to provide the socialization of harmful food for the students. The teachers should restrict the permission for the food vendor to sell at school.
\end{abstract}

Keywords: Bacillus cereus, , Food Poisoning, Outbreak, Rhodamine B, School Food

\section{PENDAHULUAN}

Keracunan makanan terjadi saat bakteri patogen jenis tertentu membawa penyakit mengontaminasi makanan termasuk di dalamnya intoksikasi makanan dapat mengakibatkan penyakit keracunan makanan. $^{1,2}$ Keracunan makanan masih menjadi masalah kesehatan di Indonesia. Pangan merupakan jalur utama penyebaran patogen dan toksin yang diproduksi oleh mikroba patogen. Pangan juga dapat menimbulkan masalah serius jika mengandung racun akibat cemaran kimia, bahan berbahaya, maupun racun alami yang terkandung dalam pangan yang sebagian di antaranya menimbulkan Kejadian Luar Biasa (KLB) keracunan pangan. ${ }^{3}$

Pada tanggal 4 Mei 2016, sekitar pukul 12.30 petugas surveilans Dinas Kesehatan Kabupaten Magelang menerima laporan dari petugas surveilans Puskesmas Bandongan adanya 21 anak Sekolah Dasar Negeri (SDN) Trasan 1 yang mengalami gejala pusing, sakit perut, mual, dan muntah. Anak yang diperiksa dengan dugaan keracunan makanan setelah mengonsumsi "cumi- 
cumian" (tepung digoreng tipis berbentuk cumi) dengan diberi rasa-rasa. Korban makan "cumi-cumian" sekitar pukul 09.00 saat istirahat sesi pertama dan mulai muncul gejala sekitar pukul 09.30 dan kemudian dibawa ke Puskesmas Bandongan pada pukul 11.30. Pada tanggal 5 dan 7 Mei 2016 tim KLB Dinas Kesehatan beserta karyasiswa FETP melakukan investigasi bertujuan untuk 1) Mengetahui gambaran besarnya KLB keracunan makanan, 2) Mengidentifikasi agen penyebab dan cara penularan yang berkontribusi terhadap kejadian KLB, 3) Melakukan tindakan pengendalian KLB sehingga dapat memberikan rekomendasi agar terhindar dari kejadian serupa.

\section{BAHAN DAN CARA PENELITIAN}

Penelitian ini menggunakan analitik deskriptif dan pemetaan sebagai gambaran lokasi sebaran kasus. Populasi studi ini adalah anak kelas 1-6 di SDN Trasan 1. Data dikumpulkan melalui: 1) Wawancara dengan panduan kuesioner terstruktur, 2) Observasi kepada semua anak yang terpapar dan tidak terpapar, 3) Pemeriksaan laboratorium terhadap sampel makanan dari sisa makanan siswa berupa cumi-cumian dan sausnya dikirim ke laboratorium Balai Besar Teknik Kesehatan Lingkungan dan Pengendalian Penyakit (BBTKL\&PP). Definisi kasus adalah anak SDN Trasan 1 yang mengalami salah satu atau lebih dari gejala pusing, sakit perut, mual, muntah pada tanggal 4 Mei 2016 setelah istirahat pertama. Sedangkan batasan kontrol adalah anak SDN Trasan 1 yang tidak mengalami gejala pusing, sakit perut, mual, muntah pada tanggal 4 Mei 2016 setelah istirahat pertama.

\section{HASIL DAN PEMBAHASAN}

Berdasarkan hasil wawancara di SDN Trasan 1 tanggal 7 Mei 2016, terdapat total 50 kasus yang diidentifikasi dari kelas $1-6$. Gejala yang dirasakan adalah pusing (77\%), mual (42\%), sakit perut (40\%), dan muntah $(8 \%)$.

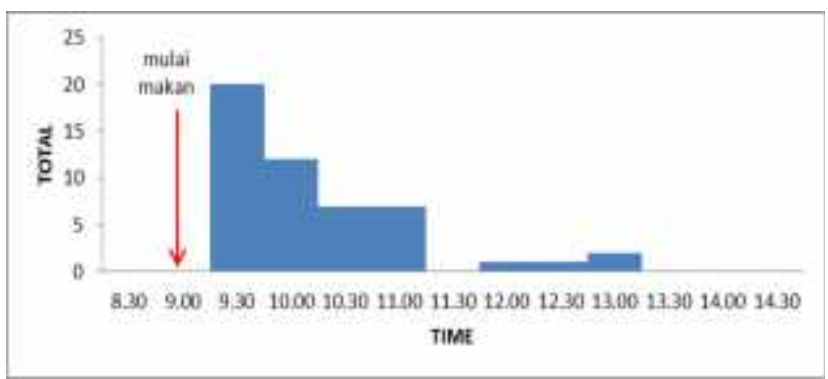

\section{Gambar 1. Kurve epidemik KLB keracunan makanan SDN 1 Trasan Bandongan, Kabupaten Magelang}

Tabel 1. Distribusi Kasus Dan Attack Rate Berdasarkan Kelas

\begin{tabular}{crrrr}
\hline Kelas & $\begin{array}{c}\text { Populasi } \\
\text { berisiko }\end{array}$ & Kasus & $\begin{array}{c}\text { Percent } \\
(\%)\end{array}$ & $\begin{array}{c}\text { Attack } \\
\text { Rate } \\
(\%)\end{array}$ \\
\hline 1 & 14 & 2 & 4 & 14,3 \\
\hline 2 & 18 & 8 & 16 & 44,4 \\
\hline 3 & 20 & 12 & 24 & 60,0 \\
\hline 4 & 22 & 10 & 20 & 45,4 \\
\hline 5 & 23 & 10 & 20 & 43,5 \\
\hline 6 & 19 & 8 & 16 & 42,1 \\
\hline Total & 116 & 50 & 100 & \\
\hline
\end{tabular}

Sumber: Data primer 2016

Gejala sakit pertama kali muncul pada pukul 09.15 tanggal 04 Mei 2016 setelah anak tersebut makan cumi-cumian pukul 09.00. Kurva berikut menunjukkan penularan penyakit secara common source dengan masa inkubasi 15-240 menit (mean 72,3 
menit). Sebagian besar kasus adalah anak laki-laki (54\%).

Attack rate berkisar antara 14,3-60 tertinggi di kelas 3 (60\%). Populasi at risk nya adalah sebanyak 116 anak dan yang sakit sebanyak 50 anak sehingga attack rate nya $50 / 116=43,1$

Tabel 2. Attack Rate Berdasarkan Jenis Makanan

\begin{tabular}{llrrr}
\hline No & $\begin{array}{c}\text { Jenis } \\
\text { Makanan }\end{array}$ & $\begin{array}{c}\text { Jumlah } \\
\text { yang } \\
\text { Makan }\end{array}$ & $\begin{array}{c}\text { Jumlah } \\
\text { yang } \\
\text { Sakit }\end{array}$ & $\begin{array}{c}\text { Attack } \\
\text { Rate } \\
\text { (\%) }\end{array}$ \\
\hline $\mathbf{1}$ & $\begin{array}{l}\text { Cumi- } \\
\text { cumian }\end{array}$ & 67 & 50 & 74,6 \\
\hline $\mathbf{2}$ & Tempura & 11 & 3 & 27,2 \\
\hline $\mathbf{3}$ & Cimol & 4 & 4 & 100 \\
\hline
\end{tabular}

Sumber: Data Primer 2016

Tabel 2 menunjukkan bahwa attack rate terbesar $100 \%$ adalah Cimol namun cimol tidak mewakili keseluruhan kasus. Attack rate yang mewakili keseluruhan kasus dan memiliki attack rate yang besar yaitu $74,6 \%$.

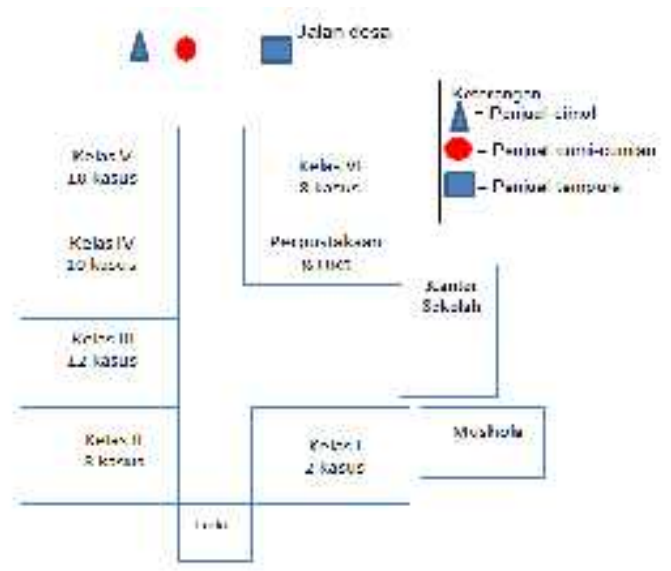

Gambar 2. Distribusi kasus berdesarkan tempat

Cara penularan pada peristiwa keracunan makanan di SDN Trasan 1 Kecamatan Bandongan yaitu siswa membeli makanan di pedagang cumi-cumian. Diduga makanan cumi-cumian tersebut sudah terkontaminasi oleh bakteri. Penularan penyakit secara common source artinya penularan keracunan makanan bersumber dari satu sumber yang berlangsung dalam waktu yang cepat dan tidak menular antar penderita.

Cumi-cumian dibuat dari bahan dasar tepung kemudian digoreng dengan minyak goreng. Setelah itu diberi saus perasa, ada rasa stroberi, bluberi, anggur, dan balado. Saus cumi-cumian ini memiliki warna yang mencolok dan jika saus terkena kulit, warnanya susah dihilangkan. Investigasi mendalam tidak dapat dilakukan karena pedagang dicari-cari kemana-mana tidak ditemukan.

Tabel 3. Hasil Pemeriksaan Sampel Makanan Cumi-Cumian

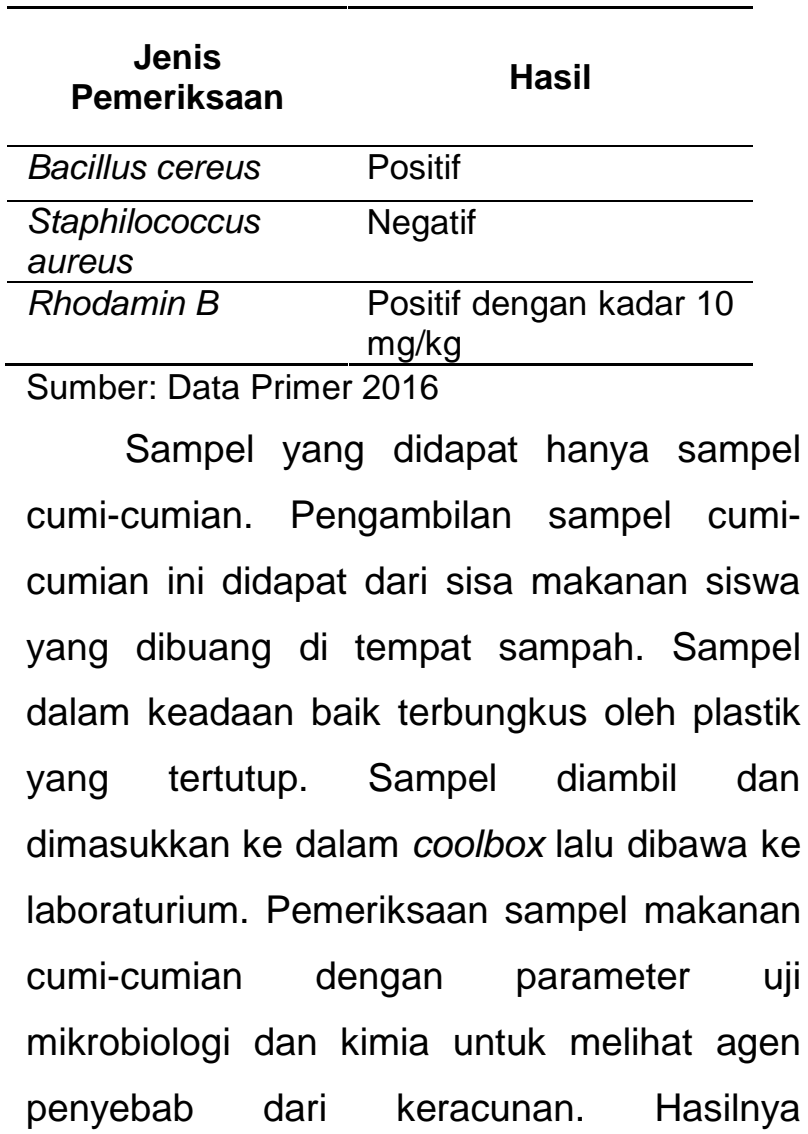


menunjukkan cumi-cumian positif Bacillus cereus dan terdapat kadar rhodamin $B$ sebesar $10 \mathrm{mg} / \mathrm{kg}$.

Tindakan yang sudah dilakukan yaitu 1) Pengobatan penderita dan edukasi perawatan yang telah dilakukan oleh tim paramedis Puskesmas Bandongan; 2) Investigasi epidemiologi dan pengambilan sampel makanan sisa makanan korban, serta mengirimkannya ke BBTKL\&PP di Yogyakarta; 3) Penyuluhan di kelas 1-6 oleh karyasiswa dan dinas kesehatan tentang jajanan yang berbahaya.

Gejala utama dan masa inkubasi pada kasus ini mengarah pada agen penyebab bakteri Staphilococcus aureus dan Bacillus cereus serta bahan kimia rhodamin $B$. Proporsi Kasus sebagian besar berjenis kelamin laki-laki. Namun, laki-laki dan perempuan memiliki proporsi yang hampir sama sehingga jenis kelamin tidak berisiko untuk menimbulkan keracunan. ${ }^{2}$ Farmashinta (2013) menyatakan bahwa keracunan makanan bukan penyakit yang menyerang salah satu organ khusus pada laki-laki atau perempuan, sehingga keracunan pangan dapat terjadi pada laki-laki dan perempuan dengan perbedaan yang acak dan dapat merata. $^{4}$ Kurva epidemik menunjukkan common source dengan satu sumber penularan dan berlangsung cepat. Gambaran gejala, masa inkubasi, dan jenis makanan maka agen penyebab paling potensial adalah Bacillus cereus didukung dengan hasil laboratorium positif Bacillus cereus.
Bacillus cereus merupakan bakteri aerobik Gramitif atau fakultatif anaerobik, motil, pembentuk spora, berbentuk batang yang tersebar luas di lingkungan. Keracunan akan timbul jika seseorang menelan bakteri atau bentuk sporanya, kemudian bakteri bereproduksi dan menghasilkan toksin di dalam usus, atau seseorang mengkonsumsi pangan yang telah mengandung toksin tersebut. ${ }^{5,6}$

Ada dua tipe toksin yang dihasilkan oleh Bacillus cereus, yaitu toksin yang menyebabkan diare dan toksin yang menyebabkan muntah (emesis). Bakteri penghasil toksin penyebab muntah bisa mencemari pangan berbahan beras, kentang tumbuk, pangan yang mengandung pati, dan tunas sayuran. Bakteri penghasil toksin penyebab diare bisa mencemari sayuran dan daging. ${ }^{6}$ Penyimpanan memiliki kemungkinan terkontaminasi spora dan pertumbuhan Bacillus cereus di bahan makanan. Kepatuhan yang ketat dengan langkahlangkah higienis standar dan persyaratan suhu selama persiapan dan penyimpanan makanan sangat diperlukan untuk mencegah wabah foodborne lanjut disebabkan oleh toksin Bacillus cereus. ${ }^{7}$

Pada umumnya, bahaya akibat pengonsumsian rhodamin $B$ akan muncul jika zat warna ini dikonsumsi dalam jangka panjang. Tetapi, perlu diketahui pula bahwa rhodamin $B$ juga dapat menimbulkan efek akut jika tertelan sebanyak $500 \mathrm{mg} / \mathrm{kg}$, yang 
merupakan dosis toksiknya. Efek toksik yang mungkin terjadi adalah iritasi saluran cerna. ${ }^{8}$

Penggunaan zat pewarna baik alami maupun buatan sebagai bahan tambahan makanan telah diatur dalam Peraturan Menteri Kesehatan RI Nomor 722/MenKes/Per/VI/88 mengenai Bahan Tambahan Makanan, sedangkan zat warna yang dilarang digunakan dalam pangan tercantum dalam Peraturan Menteri Kesehatan RI Nomor 239/MenKes/Per/V/85 mengenai Zat Warna Tertentu yang Dinyatakan sebagai Bahan Berbahaya. Dalam peraturan-peraturan tersebut, pemerintah mengatur bahan tambahan makanan apa saja yang diperbolehkan dan batas maksimum penggunaannya. Salah satu pewarna sintetis yang dilarang digunakan sebagai bahan tambahan pangan adalah Rhodamin $B^{9,10}$

\section{KESIMPULAN}

Besar kemungkinan penyebab keracunan adalah toksin yang dihasilkan Bacillus cereus karena kadar rhodamin $B$ dalam sampel terlalu kecil dapat menimbulkan keracunan akut.

Potensial cemaran diduga karena higena yang kurang baik dari pengolah makanan dan penyimpanan makanan siap kosumsi yang cukup lama yang memungkinkan bakteri Bacillus cereus memproduksi toksin yang menyebabkan keracunan.
Diharapkan Puskesmas Bandongan memberikan penyuluhan cara memproses makanan secara higienis kepada penjual makanan sekolah di Bandongan.

Diharapkan Guru SDN 1 Trasan agar mengawasi dan memperketat izin penjual makanan di sekolah dan memberikan penyuluhan kepada siswa tentang kebersihan tangan saat menjamah makanan dan keamanan pangan.

\section{TERIMA KASIH}

1. drg. Maya Kristanti selaku Kepala Puskesmas Bandongan

2. dr. Hendarto, M.Kes selaku Kepala Dinas Kesehatan Kabupaten Magelang, email: dinkes@magelangkab.go.id

\section{KEPUSTAKAAN}

1. Chin, James,. Kandun, Nyoman (Editor). Manual Pemberantasan Penyakit Menular. Jakarta: CV. Infomedika; 2009

2. WHO. http://www.searo.who.int diakses tanggal 19 Mei 2016; 2015

3. Pusat Data dan Informasi. Ketahanan Pangan Di Indonesia. Buletin Jendela Data \& Informasi (2); 2015

4. Farmashinta AR. Faktor Risiko Keracunan Makanan dari Analisa Kasus yang Dirawat Inap di Rumah Sakit Umum Daerah (RSUD) Cibinong Kabupaten Bogor Jawa Barat Tahun 2008-2012. Depok: Fakultas Kesehatan Masyarakat Universitas Indonesia; 2013

5. Bottone, E. J. Bacillus cereus, a volatile human pathogen. Clinical microbiology reviews, 2010, 23(2), 382-398.

6. Badan POM.

http://ik.pom.go.id/v2014/artikel/Keracunan -Pangan-Akibat-Bakteri-Patogen3.pdf diakses tanggal 19 Mei 2016

7. Schmid, Daniela, et al. Elucidation of enterotoxigenic Bacillus cereus outbreaks 
in Austria by complementary epidemiological and microbiological investigations, 2013. International journal of food microbiology, 2016, 232: 80-86

8. Badan POM.

http://ik.pom.go.id/v2015/artikel/Bahaya-

Rhodamin-B-sebagai-Pewarna-pada-

Makanan.pdf diakses tanggal 19 Mei 2016

9. Peraturan Menteri Kesehatan RI Nomor 722/MenKes/Per/VI/88 mengenai Bahan Tambahan Makanan.

10. Peraturan Menteri Kesehatan RI Nomor 239/MenKes/Per/V/85 mengenai Zat Warna Tertentu yang Dinyatakan Sebagai Bahan Berbahaya. 